\title{
Seminários virtuais na formação de professores: o que dizem os professores sobre as suas práticas educacionais?
}

\author{
Fernanda Maria Pereira Freire, Maria Cecília Martins \\ Núcleo de Informática Aplicada à Educação - Universidade Estadual de Campinas \\ (UNICAMP) \\ Rua Seis de Agosto, 50, Bloco V da Reitoria - $2^{\circ}$ Piso \\ 13083-873 Campinas - SP - Brazil \\ \{ffreire, cmartins\} @unicamp.br
}

\begin{abstract}
This article presents scenes of teaching and learning reported by teachers from public schools at the northern region of the country that participate in the Program One Laptop per Child. Our goal is to identify, based on what they say about their practices in Online Seminars, signs that suggest a movement toward changes in schools driven by the entry the process of teacher training and the entry of technology in their lives and in the lives of students.
\end{abstract}

Resumo. Este artigo apresenta cenas de ensino-aprendizagem relatadas por professores de escolas públicas da região norte do país que participam do Programa Um Computador por Aluno. Nosso objetivo é identificar, com base naquilo que dizem sobre as suas práticas educacionais em Seminários virtuais, sinais que sugerem um movimento em direção a mudanças nas escolas impulsionado pelo processo de formação dos professores e a entrada da tecnologia em suas vidas e na vida dos alunos.

\section{Introdução}

A formação de professores para a inserção da tecnologia no cotidiano escolar implica a redefinição de metas e de objetivos educacionais, readequação do tempo e do espaço da escola, além de seleção e avaliação sistemáticas de estratégias pedagógicas levando em conta as possibilidades tecnológicas disponíveis/conhecidas. O estabelecimento de relações de reciprocidade entre conteúdos e modos de uso das tecnologias, embora crucial para provocar mudanças nas práticas escolares, não é suficiente [Papert, 1997]. Assim, a formação de professores para o uso com sentido das tecnologias de informação e comunicação [Freire, 2012] implica concebê-la como um processo diferenciado, complexo e reflexivo [Prado e Almeida, 2009; Prado, 2009]. Embora a escola, como outras organizações complexas, resista a modificar substancialmente o seu modo de trabalho [Papert, op. cit.], nossa experiência tem mostrado que as tecnologias podem desestabilizar os processos vigentes e impulsionar mudanças no fazer pedagógico. É com esse enfoque que vimos desenvolvendo ações de formação no Programa Um Computador por Aluno (UCA).

A estrutura do Programa prevê que uma instituição de ensino superior global, denominada de IES-global, intervenha na formação de outra instituição de ensino superior local, a IES-local, que intervém, por sua vez, na formação de tutores que compõem sua equipe. Esses tutores, em geral, são provenientes dos Núcleos de 
Tecnologias Estaduais e/ou Municipais (NTEs) e atuam na preparação dos professores das escolas contempladas pelo Programa. Dessa cadeia formativa, portanto, depende a qualidade do trabalho educacional realizado nas escolas com os alunos mediado (também) pelo laptop.

A Universidade Estadual de Campinas, no papel de IES-global, participou da formação das equipes locais dos estados do Acre, Pará e Rondônia entre os anos de 2010 a 2012. A partir de 2011 a interação entre as equipes passou a ser feita à distância de duas maneiras: (i) por meio de Seminários virtuais mensais com a participação dos integrantes das 4 equipes (Acre, Pará, Rondônia e Unicamp), incluindo os professores das Universidades, dos NTEs e, eventualmente, das escolas e (ii) por meio de ferramentas de comunicação mediada por computador (CMC) para apoiar a interação entre pesquisadores da IES-global destacados para acompanhar as equipes de cada estado (um pesquisador por estado).

Os Seminários virtuais regionais previam a preparação de apresentações relacionadas a temas previamente indicados pela equipe da IES-global e escolhidos em comum acordo com as IES-locais, alguns dos quais focalizavam atividades escolares desenvolvidas pelos professores em formação. Essa preparação mobilizava todas as equipes e constituia um rico espaço para a reflexão dos professores e formadores sobre o fazer pedagógico, o aprendizado dos alunos e o próprio processo de formação. Da mesma forma, o momento posterior à realização dos Seminários, em função das discussões que se seguiam a cada apresentação, abria novas possibilidades para reformulações e ajustes nos rumos da formação e no trabalho em sala de aula.

É, pois, a partir dessa troca de vivências sobre e para a formação de professores que selecionamos, com base em uma metodologia qualitativa, três cenas de ensinoaprendizagem, cada uma delas relatada por uma das equipes, com o objetivo de identificar sinais que sugerem um movimento em direção a mudanças nas escolas, impulsionado pela formação dos professores que visava, entre outras coisas, dar sentido àa entrada da tecnologia na vida dos professores e dos alunos. É a partir da fala dos professores sobre suas práticas, considerada representativa de uma reflexão posterior sobre o que fazem, uma reflexão-sobre-a-ação nos moldes de Schön (2000), ocasião em que selecionam $o$ quê dizer e organizam como dizer, que focalizamos a nossa análise com vistas a identificar esses sinais.

\section{Contexto do estudo e metodologia}

Foram realizados, entre os anos de 2011 e 2012, 15 Seminários sobre temas variados, em um total de 45 apresentações. Antes da realização dos Seminários eram oferecidas diretrizes com antecedência às equipes, de modo que pudessem analisar o andamento dos trabalhos nas escolas e elaborar as apresentações seguindo as mesmas orientações, visando facilitar o diálogo entre todos.

Para os nossos propósitos interessam as apresentações relacionadas a temas que abordam direta ou indiretamente o trabalho pedagógico realizado pelos professores em formação. São 7 temas no total, reunindo 21 apresentações, 3 dos Seminários ocorreram no ano de 2011 e 4 no de 2012: Processos de formação: relatos de casos, Relatos de atividades de alunos usando o laptop. Análise dos impactos provocados pelo PROUCA, Analisando o papel do laptop no aprendizado do aluno, Dando continuidade à análise 
do papel do laptop no aprendizado do aluno, Aprendendo com o laptop - estudo de caso e Relato e reflexão sobre os trabalhos nas escolas dos estados do Acre, Pará e Rondônia (a listagem completa dos temas dos Seminários UCA-UNICAMP Região Norte pode ser encontrada em: http://styx.nied.unicamp.br/ucanaunicamp/encontros-deformacao).

As apresentações foram reorganizadas em função de dois fatores: (i) relatos por estado; (ii) relatos por diferentes níveis de escolaridade. $\mathrm{O}$ fator (i) considera o fato de a formação dos formadores ter sido encaminhada em cada um dos estados por um pesquisador diferente da equipe IES-global UNICAMP, considerados aqui como "representantes" de um modo específico de conceber e fazer formação de professores. Já, o (ii), considera a diversidade e abrangência que o trabalho baseado no uso da tecnologia pode ter nas escolas.

Essa espécie de categorização das apresentações nos permitiu selecionar cenas de aprendizagem que mostram os múltiplos fatores que se apresentam no processo de formação e, consequentemente, na inserção da tecnologia na escola. Selecionamos, então, para compor o corpus deste estudo, duas cenas de aprendizagem apresentadas pelas equipes do Acre e de Rondônia no $4^{\circ}$ Seminário, em agosto de 2012 e uma cena de aprendizagem apresentada pela equipe do Pará no $5^{\circ}$ Seminário, em setembro do mesmo ano. Ambas tinham como tema "o papel do laptop no aprendizado do aluno".

As análises qualitativas realizadas neste estudo se inspiram no paradigma indiciário, explicitado pelo historiador Carlo Ginzburg (1986) nas Ciências Humanas. Trata-se de um modelo epistemológico pautado no singular, no episódico, no detalhe, que guarda relação com aquilo que o investigador se propõe a compreender do ponto de vista teórico. $\mathrm{O}$ modelo define algumas questões metodológicas importantes a respeito dos critérios de identificação e seleção dos dados, bem como ao denominado rigor metodológico. Um dado é singular à medida que pode ser tomado como "representativo" de algo que é, teoricamente "revelador", já que nem tudo que é incomum é, necessariamente, singular no sentido adotado pelo modelo [Abaurre e Coudry, 2008, p. 174]. O rigor metodológico, por sua vez, tem a ver com a natureza do que se pretende investigar. Estudos como o que aqui se apresenta não podem se pautar em procedimentos experimentais, replicação de experimentos e quantificação de resultados, razão pela qual o modelo assume um "rigor flexível" (tal como o denomina Ginzburg) em que contam outros fatores, como a intuição do investigador para observar o singular, como um "caçador agachado na lama, que escruta as pistas da presa" [Ginzburg, 1986, p. 154].

No nosso caso, a questão teórica que nos motiva é verificar o modo como o processo de formação desses professores repercute na mudança de práticas em sala de aula, assumindo como posto de observação os dizeres desses profissionais. Inspiradas pelo paradigma indiciário no que se refere ao modo de selecionar e analisar dados, nos concentramos na análise de conteúdo das apresentações dos professores, nas suas falas, amparadas por um referencial teórico sobre formação de professores de base construcionista [Prado e Freire, 1996, 2001], à procura de sinais de mudança, não necessariamente, singulares como Ginzburg descreve, mas suficientemente robustos para sustentar nossa análise. 
É, pois, com esse espírito que reassistimos aos vídeos das apresentações das equipes, relemos os slides que usaram, bem como as anotações que fizemos por ocasião da realização dos Seminários (comentários e/ou perguntas e respostas formuladas por integrantes da equipe da IES-global ou das outras IES-locais) na tentativa de identificar sinais de mudança nas três cenas de aprendizagem selecionadas.

\section{Resultados e Discussão}

Nesta seção, reapresentamos os relatos das equipes de forma abreviada, devido a sua extensão, focalizando os sinais que, do nosso ponto de vista, sugerem um movimento em direção a mudanças nas escolas. Nosso objetivo não é "avaliar" a qualidade ou a adequação das atividades apresentadas. Certamente, toda atividade escolar pode ser refinada, mas o nosso propósito é tentar identificar, a partir das falas dos professores, que concepções e motivações estão implícitas na escolha daquilo que se propõem a apresentar ao grupo.

Para organizar essa reapresentação iniciamos com a cena de aprendizagem do Acre, no Colégio de Aplicação, em Rio Branco, com alunos do Pré-escolar II que têm, em média, 5 anos e compõem uma sala de aula com cerca de 21 alunos. As aulas estão a cargo de duas professoras e o tema que estava sendo tratado com os alunos era "Meios de transporte" do tipo "terrestres". Em seguida, apresentamos o relato de Rondônia a respeito da história de Inês, nome fictício de uma aluna do $9^{\circ}$ ano da EMEF Prof. Irineu Antonio Dresch, do município de Ji-Paraná, uma escola rural que atende alunos do $1^{\circ}$ ao $9^{\circ}$ ano na região de abrangência. Por último, apresentamos a cena de aprendizagem planejada por um professor de Biologia para as classes do $2^{\circ}$ ano do Ensino Médio da EE Jerônimo M. Tavares, localizada no município de Limoeiro do Ajuru, no estado do Pará.

\subsection{Cena de aprendizagem na Educação Infantil}

O objetivo das professoras do Pré-escolar II é ajudar os alunos a identificar diferentes meios de transporte que são usados no dia a dia, sejam terrestres, aéreos ou aquáticos, reconhecendo suas principais características. Em especial, naquela aula, o trabalho focalizaria os transportes terrestres, uma vez que os demais já haviam sido tematizados em aulas anteriores.

Essa temática foi inserida na rotina das aulas que, em geral, iniciam com a leitura de uma história em voz alta por uma das professoras com o intuito de despertar nas crianças o prazer pela leitura. Em seguida, as professoras fazem a chamada, momento em que os alunos são convocados a identificar seus nomes em pequenas cartelas que decoram a sala, e mostram o calendário, para que as crianças reconheçam o dia, o mês e o ano. Na sequência, as professoras conversam com os alunos sobre os meios de transporte, na tentativa de verificar o que as crianças já haviam compreendido/aprendido nas aulas anteriores sobre os meios aquáticos e aéreos. Finalmente, falam sobre alguns meios de transporte terrestres, desenham alguns deles na lousa e informam quais atividades serão realizadas no decorrer do dia.

As professoras distribuem entre as crianças conjuntos de formas geométricas desenhadas em cartolina para que montem um carro e associem cada uma de suas partes ao nome de uma figura geométrica já conhecida por elas (um círculo - uma roda; um 
retângulo - o corpo do carro; um quadrado - a janela, e assim sucessivamente). As crianças, então, pintam as figuras geométricas, recortam e colam nos cadernos de desenho os carros que montam como um quebra-cabeças. Terminada a tarefa, as crianças usam um alfabeto móvel, confeccionado por elas em outra ocasião, para formar as palavras carro, terrestre, o próprio nome e a data. As mesas dos alunos estão dispostas de tal modo que podem trabalhar colaborativamente. Em seguida, duplas de crianças, são convidadas a desenhar um "meio de transporte terrestre" usando o aplicativo Tux Paint. Uma grande diversidade de propostas surge nas telas dos laptops. As professoras circulam entre os alunos, mediando a interação entre eles e a atividade em curso.
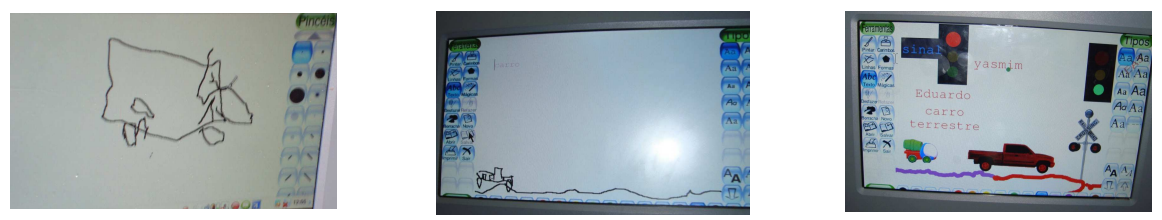

Figura 1 - Exemplos de trabalhos dos alunos no Tux Paint

Segundo a avaliação das professoras, as atividades desse dia permitiram aos alunos desenvolver a criatividade, exercitar a coordenação motora fina, explorar a leitura e a escrita, além de incentivar a colaboração entre eles. Vários processos linguísticos e cognitivos foram convocados (percepção, atenção, memória, linguagem) em meio a uma dinâmica que explora o trabalho individual e o coletivo. Por fim, todas as crianças deram mostras (pelos desenhos e perguntas que fizeram) de terem entendido o sentido de "terrestre".

Reconhecemos, a partir desse relato, alguns sinais que merecem nossa atenção e que estão relacionados ao processo de formação das professoras. A inserção do laptop se dá em meio a outras atividades que utilizam materiais variados e o seu uso "entra" de maneira natural no fluxo das atividades planejadas pelas professoras, oferecendo aos alunos outra forma de representação, diferente da que haviam feito por meio da colagem. As professoras assumem uma posição específica, organizando as atividades dos alunos, interferindo na medida em que observam suas ações. Esse lugar permite a elas perceber o envolvimento e as dúvidas dos alunos tanto para interferir quando necessário, quanto para projetar os passos subsequentes. A diversidade dos trabalhos dos alunos, seja nas colagens que fazem, seja nos desenhos que produzem com o Tux Paint, atesta a heterogeneidade dos alunos e os diferentes meios que encontram para dar conta dos desafios que lhes são apresentados. Essa constatação não é vista como um problema na condução do trabalho em sala de aula; ao contrário, a organização do espaço da sala de aula e dos alunos em duplas promove o trabalho coletivo, sem apagar as diferenças individuais. Finalmente, as professoras veem para além da materialidade do resultado final dos trabalhos dos alunos, identificando quais processos linguísticos e cognitivos são mobilizados naquele aprendizado [Vygotsky, 1987]. Assumem, assim, uma atitude reflexiva frente ao que fazem, o que lhes dá condições de prosseguir em consonância com as necessidades dos alunos e o currículo escolar.

\subsection{Cena de aprendizagem no Ensino Fundamental II}

A equipe de Rondônia relatou a história de Inês, 13 anos, aluna do $9^{\circ}$ ano da EMEF Prof. Irineu Antonio Dresch. Filha de agricultores, Inês ajuda os pais no plantio de 
hortaliças e na ordenha de animais. Para ir à escola caminha cerca de $2 \mathrm{~km}$ até o ponto de ônibus mais próximo; são cerca de $27 \mathrm{~km}$ até o seu destino, o que a obriga a sair muito cedo de casa. Inês é uma ótima aluna, embora seja obrigada a perder muitas aulas durante o período chuvoso: as condições da estrada impedem o tráfego de veículos. Inês tem dois irmãos que estudam na mesma escola, sendo que um deles apresenta deficiência múltipla. Inês tem usado em casa o laptop com a irmã, que se encanta com a novidade e diz o nome dos carimbos do Tux Paint.

Inês frequenta essa escola desde o $1^{\circ}$ ano e é conhecida pelos professores que também estão há muitos anos na instituição. Inês participa de todas as atividades que são oferecidas na escola: Projeto Rádio-escola, Aluno-monitor, Projeto Jornal Escolar. Com a introdução do Programa UCA, pode aprender a usar várias ferramentas do laptop: cria slides para apresentação de trabalhos e realiza pesquisas na Internet. Perguntada sobre a importância do Programa UCA para a sua vida, Inês diz que "ele trouxe oportunidades iguais para os alunos da zona rural que não tem acesso à Internet e à tecnologia" e que agora tem a "chance de aprender mais e concorrer igualmente para conquistar uma vaga no ensino superior". Animada, continua: "agora tenho e-mail, sei ler e enviar mensagem, sei também o que é um blog". Inês participa ativamente do blog criado pela sua turma (Figura 2).

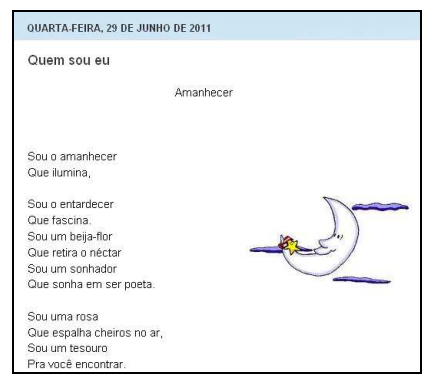

Figura 2 - Post da Inês no Blog Dosoitavo.ab

Diferentemente da proposta do Acre, que apresentou um dia em sala de aula, a equipe de Rondônia apresentou uma história particular. Histórias mostram percursos, processos, a partir dos quais podemos perceber, por um lado, fatores recorrentes e, por outro, fatores inusitados. A história de Inês mostra algumas de suas características como aprendiz - dedicada, entusiasta, envolvida - o que confere qualidade a sua relação com a aprendizagem, aberta a novos fazeres e saberes. Mostra, ainda, um sujeito que assume diferentes papéis nas diversas práticas sociais das quais participa: como aluna, ao aprender a usar email e blog; como apoiadora da aprendizagem de sua irmã, ao dividir com ela seus saberes sobre o uso do laptop; como filha, ao participar do trabalho familiar.

A escola, ao acolher as histórias de seus alunos, se constitui como lugar de cruzamento de memórias pessoais e memórias de outros tempos, outros sujeitos, outras culturas, em meio a diferentes práticas sociais do nosso tempo, promovendo o aprendizado abrangente e autônomo de seus alunos (Coudry e Freire, 2005). Os alunos envolvidos em práticas sociais desenvolvidas com apoio da tecnologia - Projeto Rádioescola, Aluno-monitor, Projeto Jornal Escolar, Blog da turma - ganham outros interlocutores e alcançam novos espaços. Inês sabe disso quando diz que poderá concorrer de igual para igual com outros alunos por uma vaga no ensino superior. Ela 
sabe que a tecnologia poderá ser um instrumento de transformação na sua vida em busca da realização de seu sonho e na conquista de seus direitos como cidadã que é.

Chama ainda a atenção o fato de a escola conseguir manter um mesmo corpo docente há vários anos: as suas histórias, certamente, fazem diferença na história da escola e na história dos alunos.

\subsection{Cena de aprendizagem no Ensino Médio}

O professor de Biologia da EE Jerônimo M. Tavares do município de Limoeiro do Ajuru, no interior do estado do Pará, decidiu usar blogs com suas turmas visando desenvolver nos alunos uma atitude diante da preservação dos recursos naturais pensando nas gerações futuras, incentivando-os a debater questões relacionadas a ação do homem no meio ambiente, suas causas e consequências, dando ênfase ao ecossistema local.

Partindo das diretrizes curriculares referente ao conteúdo $O$ homem e o ambiente e considerando as características do ecossistema limoeirense, o professor focalizou o conceito de sustentabilidade como meio de garantir a utilização dos recursos naturais da região e elaborou atividades de modo que os alunos pudessem identificar alguns agentes causadores de diferentes tipos de poluição e degradação do meio ambiente. Para facilitar a preparação das aulas, o professor elaborou uma metodologia de trabalho, dividida em etapas, bem como um cronograma (Tabela 1). Com propósito semelhante, preparou um documento que foi distribuído aos alunos do $2^{\circ}$ ano do EM, com o objetivo de ajudá-los a organizar suas atividades.

Tabela 1 - Trechos do Cronograma/Metodologia

\begin{tabular}{|c|l|}
\hline Datas & \multicolumn{1}{|c|}{ Metodologia/Etapas } \\
\hline 24 a 28/10 & $\begin{array}{l}\text { Aula expositiva sobre o homem e o meio ambiente: sustentabilidades, poluição } \\
\text { ambiental, energias renováveis, mudanças climáticas e disponibilidade de água no } \\
\text { planeta }\end{array}$ \\
\hline $\begin{array}{c}\text { 31/10 a } \\
04 / 11(\ldots)\end{array}$ & $\begin{array}{l}\text { Divisão das turmas em três grupos, apresentação das tarefas, escolha dos temas e } \\
\text { criação dos blogs (...) }\end{array}$ \\
\hline $28 / 11$ a & Postagens semanais, individuais e coletivas até o término do bimestre \\
\hline $16 / 12$ & \\
\hline 19 a 23/12 & $\begin{array}{l}\text { Os alunos serão avaliados de acordo com o seu desempenho na execução das tarefas } \\
\text { no decorrer da elaboração do blog, através da constatação das postagens } \\
\text { individuais, assim como a participação na publicação das postagens do grupo }\end{array}$ \\
\hline
\end{tabular}

Em resposta à proposta do professor, os alunos criaram blogs sobre vários temas relacionados ao conteúdo, como se pode ver na Figura 3.
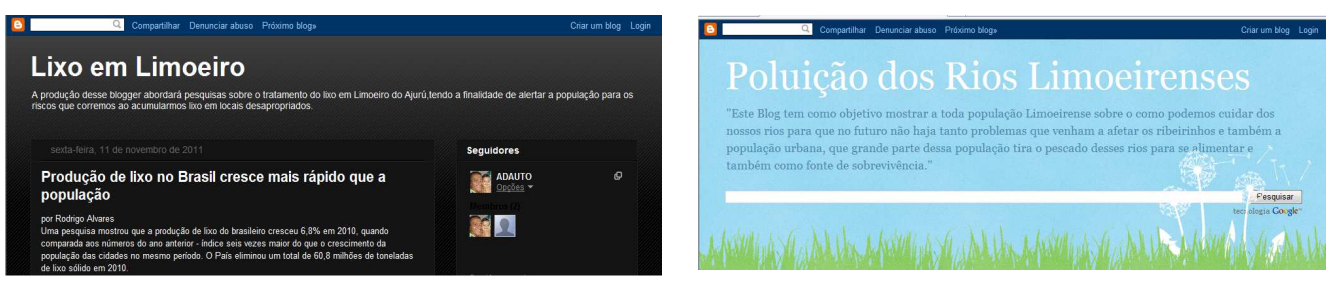

Figura 3 - Diferentes propostas de blog 
O relato do Pará mostra o planejamento de uma prática pedagógica específica que coloca o aluno no centro do processo educativo de forma ativa, ao envolvê-lo na elaboração de pesquisas, em debates com seus pares, na formulação de roteiros, na entrevista com pessoas da comunidade. Dessa forma, ao elaborar os planos de aula, o professor integra os conteúdos curriculares ao entorno dos alunos, convocando-os a estabelecer conexões entre a escola e a vida por meio de uma postura crítica diante dos problemas que a sociedade enfrenta.

Ao especificar procedimentos metodológicos e cronograma, o professor estabelece metas a serem alcançadas, descrevendo o quê pretende fazer, como e por quê, destacando os conteúdos curriculares envolvidos, as habilidades e competências que pretende mobilizar nos alunos. Além de clarificar suas intencionalidades, o plano apresenta referências aos alunos a respeito dos conteúdos em estudo, orientando suas ações para alcançar seus objetivos (trabalho em grupo, postagens individuais e coletivas no blog etc). Assim, os alunos sabem o que é esperado a cada etapa do processo e sabem de onde estão partindo e para onde vão. $O$ trabalho do professor com os alunos tem uma direção, compartilhada por todos. Ao dar visibilidade a processos, produtos, ações e demandas, professor e alunos vão pouco a pouco alinhando significados e contratos sobre os fazeres, expectativas de resultados e formas de avaliação da participação dos alunos.

A ferramenta escolhida pelo professor para os alunos socializarem seus trabalhos - o blog - e a forma como encaminha as atividades dos alunos - postagens individuais e coletivas - favorece o exercício da escrita dos alunos e, pouco a pouco, dá indícios a respeito do que sabem, pensam e aprendem. As postagens dos diferentes blogs formam, no decorrer do processo, um amplo espaço de informação e de colaboração, trazendo à tona opiniões, visões e reflexões sobre a temática em estudo pelo grupo.

\section{Considerações Finais}

A releitura das cenas de ensino-aprendizagem, a partir de um ponto de vista, parece não trazer grandes inovações. Os sinais que nelas identificamos - reconhecimento da heterogeneidade dos alunos e dos modos de aprender, papel mediador do professor e da tecnologia utilizada nas atividades, convivência de atividades que usam tecnologia e que não usam tecnologia, avaliação sistemática das ações dos alunos em sala de aula, planejamento prévio de atividades ajustadas aos alunos e ao currículo, estabelecimento de acordos com os alunos sobre a condução das atividades e sua avaliação, abertura do espaço de aprendizagem para além das salas de aula, entre outros - não são estranhos ao contexto escolar. Ao contrário, todos fazem parte do que reconhecemos como escola.

Ocorre que, em função do acúmulo de tarefas que lhe tem sido atribuídas em função das transformações sócio-econômicas do nosso tempo, a escola, na maioria das vezes, não tem tratado de sua função primordial com o devido cuidado: ensinar com qualidade. Essa escola tem sido o lugar do mesmo: "não há lugar para o imprevisível, a invenção, para novas relações de conhecimento. Isso pressupõe (...) uma determinada prática escolar (...) pautada na repetição, em treinos que demandam memorização de itens, cópias, respostas que repetem fórmulas. O aluno acumula um conjunto de informações que não fazem sentido para ele e que, portanto, não são aplicáveis na vida em sociedade. Isso se perpetua por meio de uma avaliação que cobra do aluno respostas 
corretas e memorizadas a questões padronizadas cuja finalidade é (re)enquadrá-lo na próxima série" [Coudry e Freire, 2005]. Os sinais que identificamos nas falas das equipes, embora não sejam necessariamente originais, indicam caminhos que rompem com essa padronização de concepões e práticas destituídas de sentido tanto para o professor, quanto para os alunos: vimos sujeitos em movimento que desejam mudanças.

Vimos ainda, outros sinais, novos, motivados pelo uso da tecnologia. Além do registro das atividades produzidas pelos alunos - fotos, vídeos, blogs, slides - o uso da tecnologia ampliou o espaço escolar em duas direções: para dentro e para fora da escola. Dentro da escola, dinamizou relações, incentivou o trabalho entre as pessoas, definiu outras dinâmicas de trabalho. Fora da escola, permitiu o estabelecimento de novos contatos, o conhecimento (virtual) de outros lugares e outros tempos, a divulgação (para muitos) do que a escola e seus alunos fazem/produzem. Registrar o que se faz e ampliar as interações fazem diferença - para melhor - no processo de ensino-aprendizagem. Criam-se, assim, outras memórias e outras relações.

Certamente, alguns poderão dizer que esse movimento em direção à mudança ocorre durante a formação dos professores, mas não se sustenta. De fato, em vários contextos, terminado o curso de formação dos professores, a escola e seus problemas recorrentes - rotatividade de professores, falta de tempo para ações de formação continuada, sobrecarga de atribuições, falta de suporte e manutenção dos equipamentos - exercem uma força contrária que inibe a efetivação de mudanças. O efeito da formação dos professores na estrutura escolar é, nesse sentido, imprevisível; mas acreditamos, ainda assim, que é possível reinventar os processos de ensinar e aprender, revisar os papéis de gestores, professores e alunos, recriar o currículo e os processos de avaliação vigentes. Essa crença tem fundamento. Concluídas as ações do Programa UCA previstas para o biênio 2011-2012 acompanhamos com satisfação, por meio da rede social Facebook, notícias do Acre que nos dão novos sinais de que o trabalho nas escolas continua a todo vapor (Figura 4).

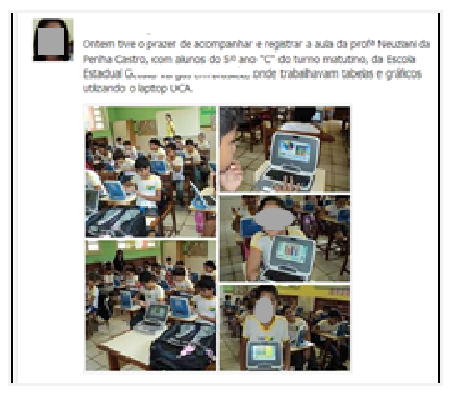
Figura 4 - Post de uma formadora do NTE de Rio Branco sobre o Programa UCA
em uma escola no município de Brasiléia em 08/08/2013.

\section{Referências}

Abaurre, M. B. M. ; Coudry, Maria Irma Hadler (2008). Em torno de sujeitos e olhares. Estudos da Língua(gem) (Impresso), v. 6, p. 173-193, 2008.

Andrade, A. (2012) "Projeto UCA: Blogs do Ecossistema Limoeirense", http://styx.nied.unicamp.br/ucanaunicamp/encontros-de-formacao/norte-2012-vseminario-de-acompanhamento-e-avaliacao-11-set-2012, Setembro. 
Chalub, S. (2012) "Aula na turma do Pré Escolar II"”, http://styx.nied.unicamp.br/ucanaunicamp/encontros-de-formacao/iv-seminario-deacompanhamento-e-avaliacao-uca-unicamp-regiao-norte-ac-pa-ro, Agosto.

Coudry, M. I. H.; Freire, F. M. P. (2005) O trabalho do cérebro e da linguagem: a vida e a sala de aula, Campinas, Cefiel/IEL/Unicamp, Linguagem e Letramento em foco.

Freire, F. M. P. (2012) "Escola e tecnologia: um olhar discursivo sobre essa complexa relação" In II Congresso Internacional TIC e Educação, Lisboa, Instituto de Educação da Universidade de Lisboa, p. 513-533.

Ginzburg, C. (1986) Sinais: raízes de um paradigma indiciário. In: Ginzburg, C. Mitos, Emblemas, sinais: Morfologia e História. São Paulo: Companhia das Letras. p. 143180 .

Martines, E. A. L. M. (2012) "Casos de alunos do projeto UCA/RO", http://styx.nied.unicamp.br/ucanaunicamp/encontros-de-formacao/iv-seminario-deacompanhamento-e-avaliacao-uca-unicamp-regiao-norte-ac-pa-ro/apresentacoes-dasequipes, Agosto.

Papert, S. (1997). Why school reform is impossible. In: The journal of the learning sciences, v. 6, n. 4, p. 417-427.

Prado, M. E. B. B. (2009). Educação a Distância na e para a formação reflexiva do professor. In ETD: Educação Temática Digital, v. 10, p. 203-222. Faculdade de Educação UNICAMP.

Prado, M. E. B. B.; Almeida, M. E. B. (2009) "Formação de Educadores: Fundamentos reflexivos para o contexto de Educação a Distância”, Educação a Distância - Prática e Formação do Profissional reflexivo, J. A. Valente e S. B. V. Bustamante, São Paulo, Avercamp, p. 65-82.

Prado, M. E. B. B. ; Freire, F. M. P. (2001) A formação em serviço visando a reconstrução da prática educacional. In: Freire, F. M. P.; Valente, J. A. (Org.). Aprendendo para a vida: os computadores na sala de aula. São Paulo: Cortez Editora, 2001, v. , p. 53-74.

Prado, M. E. B. B.; Freire, F. M. P. (1996) Da repetição à recriação: uma análise da ormação do professor para uma Informática na Educação. In: Valente, J. A.. (Org.). $O$ Professor no Ambiente Logo: formação e atuação. Campinas: Gráfica Central da Unicamp, p. 134-160.

Schön, D.A. (2000) Educando o Profissional Reflexivo: um novo design para o ensino e a aprendizagem. Trad.Roberto Cataldo Costa. Porto Alegre: Artmed, 256p.

Vygotsky, Lev Semyonovich (1987) Pensamento e Linguagem. São Paulo: Martins Fontes. 